\title{
Qualidade da água e estimativa da carga orgânica máxima assimilada pelo Córrego Lanoso
}

\author{
Water quality and estimation of maximum organic load \\ assimilated by the Lanoso stream
}

Carlos Eduardo Borges Oliveira ${ }^{1}$; Caroline Fávaro Oliveira ${ }^{1}$; Felipe Fiochi Pena ${ }^{1}$; Helen Sandra de Sousa Laet ${ }^{1}$; Isabella Esper Tamburus ${ }^{1}$; Pedro Silva ${ }^{1}$; Julio Cesar de Souza Inácio Gonçalves²; Deusmaque Carneiro Ferreira ${ }^{2}$

\footnotetext{
${ }^{1}$ Aluno do Programa de Mestrado Acadêmico em Ciência e Tecnologia Ambiental, Universidade Federal do Triângulo Mineiro, Uberaba, Minas Gerais, Brasil. E-mail: kkoliveira1@me.com; caroline_favaro@hotmail.com; ffpena@hotmail.com; helen.laet_ambiental@hotmail.com; isabelaesper@hotmail.com; pedro.s.ls@hotmail.com;

${ }^{2}$ Professor do Programa de Pós-Graduação em Ciência e Tecnologia Ambiental, Universidade Federal do Triângulo Mineiro, Uberaba, Minas Gerais, Brasil. Orcid: http://orcid.org/0000-0001-9338-0863 E-mail: sig.julio@gmail.com; deusmaque.ferreira@uftm.edu.br
}

RESUMO: Os modelos matemáticos têm considerável aplicabilidade na esfera ambiental e, dentre os usos possíveis, pode-se destacar a aferição de parâmetros de qualidade da água com a simulação de diversos cenários, o que os tornam uma importante ferramenta para a gestão dos recursos hídricos. 0 objetivo do presente estudo foi avaliar a qualidade da água do Córrego Lanoso, no município de Uberaba (MG), bem como inferir a carga máxima de efluente admissível no córrego por meio do modelo QUAL2K. As coletas foram realizadas em quatro pontos de amostragem ao longo do Córrego Lanoso. Foram analisados os seguintes parâmetros: vazão, turbidez, $\mathrm{pH}$, condutividade, oxigênio dissolvido, $\mathrm{DBO}_{5}, \mathrm{DQO}$, alcalinidade, acidez, potássio, cloreto, fósforo total, nitrato, sólidos totais, cor, temperatura. A modelagem do processo de autodepuração foi realizada com o uso do modelo QUAL2K. Mediante aos resultados das análises de vazão e dos parâmetros físico-químicos de qualidade da água,o modelo QUAL2K simulou diversos tipos de cenários do Córrego Lanoso, sendo possível estimar a capacidade máxima de suporte do curso d'água, bem como os possíveis impactos da implantação de diversas atividades agropecuárias ao longo do seu leito, sem alterar as suas características atuais. A carga máxima admissível pelo Córrego Lanoso foi de $288 \mathrm{~g} . \mathrm{s}^{-1}$ para efluente hipotético com carga máxima de $24.883 .200 \mathrm{~g}_{\mathrm{dia}}{ }^{-1}$. Os pontos a jusante da bacia apresentaram maior capacidade para depuração da carga poluidora.

Palavras-chave: Autodepuração; Modelagem matemática; QUAL2K; Gestão hídrica.

ABSTRACT: Mathematical models have considerable applicability in the environmental sphere and, among the possible uses, it is possible to emphasize the measurement of water quality parameters with the simulation of several scenarios, which make them an important tool for the management of water resources. The objective of the present study was to evaluate the water quality of the Lanoso Stream in the city of Uberaba (MG), as well as to infer the maximum permissible effluent load in the stream using the QUAL2K model. The samples were collected at four sampling points along the Lanoso stream. The following parameters were analyzed: flow, turbidity, $\mathrm{pH}$, conductivity, dissolved oxygen, BOD5, COD, alkalinity, acidity, potassium, chloride, total phosphorus, nitrate, total solids, color, temperature. The modeling of the autodepuration process was performed using the QUAL2K model. The QUAL2K model simulated several types of scenarios in the Lanoso stream, and it was possible to estimate the maximum support capacity of the watercourse, as well as the possible impacts of the watercourse implementation of several agricultural activities along its bed, without changing its current characteristics. The maximum allowable load for the Lanoso stream was $288 \mathrm{~g} . \mathrm{s}^{-1} \mathrm{for}$ hypothetical effluents with a maximum load of 24,883,200 g.day $^{-1}$. The points downstream of the basin presented greater capacity for purification of the pollutant load.

Keywords: Autodepuration; Mathematical modeling; QUAL2K; Water management.

DOI: 10.18554/rbcti.v4i3.3396 
INTRODUÇÃO

A qualidade da água pode ser representada através de diversos parâmetros, que traduzem as suas principais características físicas, químicas e biológicas. Nesse contexto, para que haja uma gestão adequada dos recursos hídricos, o primeiro passo é o monitoramento da qualidade da água, a fim de caracterizar aspectos físico-químicos que permitem diagnosticar as mudanças ocasionadas por ações antrópicas ou naturais, no uso e na ocupação da terra (QUEIROZ et al., 2010).

O estudo ambiental ou o monitoramento ambiental, em uma microbacia hidrográfica, da qualidade da água segundo os parâmetros físico-químicos é fundamental, para que, a partir das informações observadas e coletadas, seja possível um levantamento das verdadeiras influências de cada processo que venha alterar as propriedades físicas, químicas e biológicas do recurso hídrico em avaliação (SILVA, 2009).

De acordo com Salla et al. (2013) para que haja o desenvolvimento sustentável e o uso racional de água é necessário que ocorra uma relação entre a quantidade e a qualidade da água. Sendo assim, diante da necessidade de melhorar a gestão dos recursos hídricos e prever as possíveis modificações do ambiente, os modelos matemáticos se tornaram ferramentas muito importantes, que dão esse suporte tanto na gestão, quanto na prevenção dos impactos que podem interferir na qualidade da água.

O modelo matemático pioneiro de qualidade da água foi desenvolvido por Streeter e Phelps em 1925 no Rio Ohio, e foi utilizado para prever o déficit da concentração de oxigênio no corpo receptor, causado pela descarga de águas residuárias.

Ao longo dos anos, houve um grande esforço científico pela busca e aprimoramento de novos modelos, com maior complexidade e números de variáveis modeladas para expressar matematicamente e simular os diversos processos que envolvem as alterações químicas, físicas e biológicas de um curso d'água (FLECK; TAVARES; EYNG, 2013).

Por isso, atualmente há inúmeros modelos matemáticos para a simulação da qualidade da água e a escolha pelo modelo mais adequado, deve ser avaliada em concordância com as especificidades do pesquisador e da área em estudo (FRAGA et al., 2016).

O modelo matemático utilizado neste trabalho foi o QUAL2K, o qual foi criado inicialmente por Chapra (2006) e distribuído pela USEPA (United States Environmental Protection Agency) e vem sendo amplamente utilizado em estudos que envolvem a modelagem da qualidade da água em rios (FRAGA et al., 2016).

Segundo Bottino (2008), esse modelo mostrou-se muito eficaz para a simulação da qualidade da água e condições hidrológicas em pequenos rios, como também na avaliação desses corpos com interferências de cargas pontuais ou difusas de efluentes.

O objetivo do presente estudo foi avaliar a qualidade da água do Córrego Lanoso, no município de Uberaba (MG), bem como inferir a carga máxima de efluente hipotético admissível no córrego por meio do modelo QUAL2K.

\section{MÉTODO}

A área objeto do presente estudo foi o Córrego Lanoso, que integra a sub-bacia do Rio Uberaba que drena o município de Uberaba, localiza-se na micro região do Triângulo Mineiro, em Área de Proteção Ambiental (APA) do Rio Uberaba, estado de Minas Gerais. 
O supracitado córrego integra a APA do Rio Uberaba, criada por meio da Lei Estadual n. 13.183 de 21 de janeiro de 1999, que compreende uma área de $535 \mathrm{~km}^{2}$ (ABDALA, 2005). Seu principal objetivo é a conservação da biodiversidade, a fim de permitir a utilização dos recursos naturais de forma sustentável, estabelecendo modelos de desenvolvimento e, garantindo a qualidade e quantidade de água para o abastecimento público do município, bem como estabelecendo diretrizes de uso do solo e comportamento socioeconômico da área.

A cidade de Uberaba encontra-se na microrregião do Triângulo Mineiro (1945'27"S 475'36"'O) com uma área física total de 4.529,70 km², sendo drenada pela sub-bacia do Rio Uberaba. O Rio Uberaba é o principal afluente dessa sub-bacia, com 237.450 hectares de área, cuja nascente situa-se numa região de planalto (altitude de 1012 metros), nas proximidades do trevo de Ponte Alta na BR 262, alcançando sua foz no Rio Grande após $140 \mathrm{~km}$. Os principais afluentes na Área de Proteção Ambiental (APA) do Rio Uberaba são os córregos dos Pintos, da Saudade, Borá, Alegria e Lanoso (SEMAM, 2007). Destaca-se que a sub-bacia do Rio Uberaba é a principal fonte de abastecimento de água para a cidade de Uberaba.

Segundo Pina et al. (2016) a sub-bacia do Córrego Lanoso tem seu ponto mais alto situado no chapadão (altitude de 930 metros) e o ponto mais baixo na altitude de 745 metros, com um desnível máximo de 185 metros. Possui área aproximada de 2.103,75 hectares e encontra-se nas seguintes coordenadas: Latitude $19^{\circ} 37^{\prime} 59.79$ 'S e Longitude $47^{\circ} 57^{\prime} 30.55^{\prime \prime} \mathrm{O}$.

A microbacia do Córrego Lanoso apresenta uma forma alongada, sendo menos susceptível a ocorrência de enchentes, apresentando sinuosidade baixa $(1,16)$ que favorece a maior velocidade na dispersão de poluentes, associado ainda às baixas declividades do curso de água principal $(1,50 \%)$ e da bacia $(1,86 \%)$, reduzindo assim as possibilidades de ocorrência dos processos erosivos no leito do Córrego Lanoso (TORRES et al., 2008).

Em relação ao uso e ocupação do solo, a sub-bacia do Córrego Lanoso caracteriza-se pelo uso predominante de pastagens para pecuária extensiva, seguida pela área coberta por vegetação nativa, onde as maiores partes das Áreas de Preservação Permanente encontram-se conservadas. Além disso, há áreas pontuais onde são desenvolvidas as atividades de agricultura, na qual a cultura predominante é a cana de açúcar (Figura 1).

As coletas de água para o monitoramento dos parâmetros de qualidade da água foram realizadas quinzenalmente no Córrego Lanoso de fevereiro a agosto de 2018.Os procedimentos de coleta, tempo para análises e armazenamento das amostras foram seguidos na íntegra conforme descrito no Standart Methods for the Examination of Water and Westewater, 20th edition (APHA, 2008).

Foram selecionados quatro pontos para amostragem ao longo do percurso do Córrego Lanoso (Figura 1). O ponto 1 (P1) encontra-se à montante, próximo a nascente em área de vegetação nativa, menor intervenção antrópica, ponto controle. O ponto 2 (P2) do Córrego Lanoso está em área com predomínio de pastagem (criação extensiva de gado bovino). $\mathrm{O}$ ponto 3 (P3) está nas proximidades de área agrícola (cultivo de cana-deaçúcar). $\mathrm{O}$ ponto 4 (P4) encontra-se à jusante, cujas proximidades há áreas agrícolas e de pastagem. 
Figura 1. Bacia do Córrego Lanoso, Uberaba-MG.

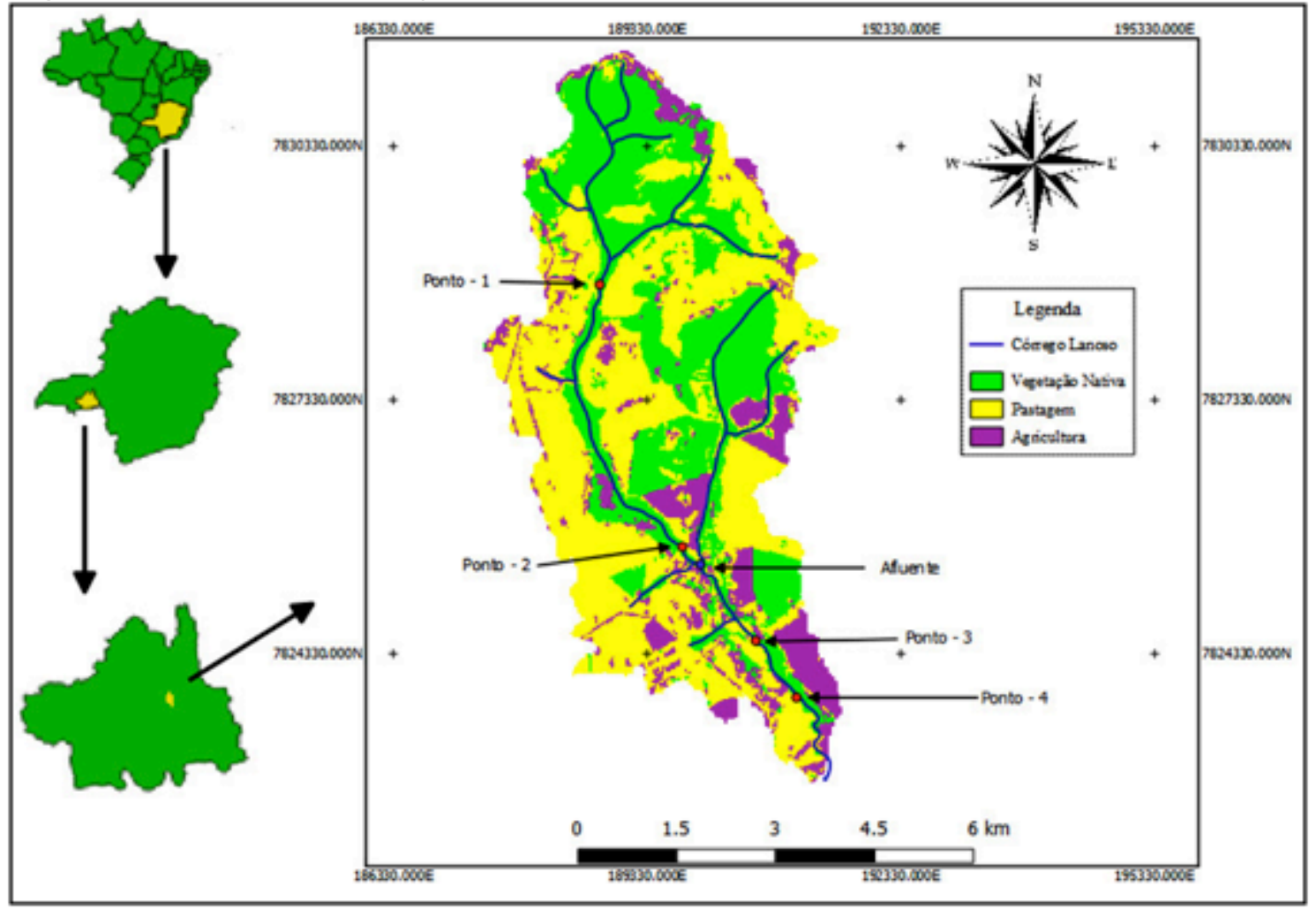

As variáveis físico-químicas analisadas foram: temperatura $\left({ }^{\circ} \mathrm{C}\right), \mathrm{pH}$, oxigênio dissolvido $\left(\mathrm{mg}^{\mathrm{L}} \mathrm{L}^{-1}\right)$, turbidez (NTU), condutividade $\left(\mu \mathrm{s} . \mathrm{cm}^{-1}\right)$, sólidos totais $\left(\mathrm{mg} . \mathrm{L}^{-1}\right)$, cor (uC), demanda bioquímica de oxigênio $\left(\mathrm{mg} \cdot \mathrm{L}^{-1}\right)$, Demanda química de oxigênio (mg. $\left.\mathrm{L}^{-1}\right)$, nitrato $\left(\mathrm{mg} \cdot \mathrm{L}^{-1}\right)$, potássio $\left(\mathrm{mg} \cdot \mathrm{L}^{-1}\right)$, cloreto $\left(\mathrm{mg} \cdot \mathrm{L}^{-1}\right)$, dureza $\left(\mathrm{mg} \cdot \mathrm{L}^{-1}\right)$, acidez $\left(\mathrm{mg} \cdot \mathrm{L}^{-1}\right)$, alcalinidade $\left(\mathrm{mg} \cdot \mathrm{L}^{-1}\right)$, fósforo total $\left(\mathrm{mg} \cdot \mathrm{L}^{-1}\right)$.

As medidas de temperatura, $\mathrm{pH}$ e oxigênio dissolvido foram realizadas in situ por meio de sonda digital (Hachlntelicall). Os Sólidos Totais (ST) foram analisados pela metodologia gravimétrica de acordo com Standart Methods for the Examination of Water and Weste water, 20th edition (APHA, 2008).

A leitura de cor foi realizada pelo método colorimétrico em $430 \mathrm{~nm}$. A Demanda Química de Oxigênio (DQO) foi realizada colorimetricamente a $600 \mathrm{~nm}$. As absorbâncias das análises de cor e DQO foram realizadas em espectrofotômetro da marca Biospectro SP-22 do Laboratório de Saneamento Ambiental da Universidade Federal do Triângulo Mineiro.Essas análises foram realizadas de acordo com os padrões Standart Methods for the Examination of Water and Weste water, 20th edition (APHA, 2008).

As medidas de turbidez foram feitas por meio de um turbidímetro de bancada digital (Lab 1000), as leituras de condutividade elétrica foram feitas a partir de um condutivímetro de bancada (mCA-150, MsTecnopon). As análises de nitrato, potássio e fósforo total foram realizadas a partir de sondas de eletrodo específico (Laquatwin da marca Horiba).

Para análise de $\mathrm{DBO}_{5}$ foi utilizado o método respirométrico de acordo Standart Methods for the Examination of Water and Weste water, 20th edition (APHA, 2008). Os parâmetros cloreto, dureza, acidez e alcalinidade foram feitos pelo método volumétrico, no qual utilizou-se como titulante $\mathrm{AgNO}_{3}$ a $0,05 \mathrm{~mol}^{\mathrm{L}} \mathrm{L}^{-1}$. EDTA a $0,001 \mathrm{~mol} \cdot \mathrm{L}^{-1}, \mathrm{NaOH}$ a 0,02 mol.L ${ }^{-1} \mathrm{e}_{2} \mathrm{SO}_{4}$ a 0,02 mol. $\mathrm{L}^{-1}$, respectivamente. 
Em função da acessibilidade e das características físicas e topográficas do local, a vazão do Córrego Lanoso foi determinada somente nos pontos 1 e 3, por meio de medição direta com o uso do molinete (CARVALHO, 2008).

Para a simulação dos cenários de carga máxima assimilada para cada ponto do Córrego Lanoso utilizou-se o modelo matemático QUAL2K, fornecido pela USEPA (United States Environmental Protection Agency). Para a estimativa da carga máxima assimilada em cada trecho do Córrego Lanoso, os valores de entrada de vazão e concentração foram testados (simulando um lançamento de carga pontual) visando a redução do OD até $5 \mathrm{mg} \cdot \mathrm{L}^{-1}$. A calibração do modelo foi determinada ajustando o coeficiente $\mathrm{K}_{2}$ (coeficiente de reaeração atmosférica), de modo que o modelo reproduzisse as concentrações reais, coletadas in situ, para o oxigênio dissolvido.

\section{RESULTADOS E DISCUSSÃO}

$\mathrm{Na}$ Tabela 1 constam os valores médios dos resultados dos parâmetros de qualidade da água obtidos nos quatro pontos de amostragens no Córrego Lanoso e as médias de vazão para os pontos 1 e 3 .

Tabela 1. Parâmetros de qualidade da água analisados e média das vazões nos pontos de amostragens no Córrego Lanoso

\begin{tabular}{|c|c|c|c|c|}
\hline PARÂMETROS & P1 & P2 & P3 & P4 \\
\hline $\mathrm{pH}$ & $7,0 \pm 0,1$ & $7,0 \pm 0,1$ & $7,2 \pm 0,1$ & $7,6 \pm 0,1$ \\
\hline Temperatura $\left({ }^{\circ} \mathrm{C}\right)$ & $25,4 \pm 0,3$ & $24,8 \pm 0,2$ & $25,2 \pm 0,2$ & $26,1 \pm 0,1$ \\
\hline Turbidez (UNT) & $1,9 \pm 0,2$ & $3,7 \pm 0,1$ & $3,2 \pm 0,2$ & $7,2 \pm 0,1$ \\
\hline Condutividade $\left(\mu \mathrm{S} . \mathrm{cm}^{-1}\right)$ & $196,3 \pm 0,2$ & $118,1 \pm 0,2$ & $102,1 \pm 0,1$ & $72,9 \pm 0,3$ \\
\hline OD (mg. $\left.L^{-1}\right)$ & $7,4 \pm 0,1$ & $7,5 \pm 0,1$ & $7,8 \pm 0,1$ & $9,3 \pm 0,1$ \\
\hline Saturação de OD (\%) & $91,3 \pm 1,2$ & $94,5 \pm 1,2$ & $98,2 \pm 1,2$ & $101,4 \pm 1,2$ \\
\hline Sólidos Totais (mg.t-1 $)$ & $82,0 \pm 2,2$ & $170,0 \pm 1,8$ & $110,0 \pm 2,2$ & $60,0 \pm 0,8$ \\
\hline Cor (uC) & $25,8 \pm 0,1$ & $71,3 \pm 0,1$ & $62,2 \pm 0,1$ & $955,4 \pm 0,1$ \\
\hline DQO (mg. $\left.L^{-1}\right)$ & $122,8 \pm 1,1$ & $135,6 \pm 1,5$ & $139,6 \pm 1,3$ & $109,0 \pm 1,2$ \\
\hline $\mathrm{DBO}_{5}\left(\mathrm{mg} \cdot \mathrm{L}^{-1}\right)$ & $70,5 \pm 1,0$ & $77,0 \pm 1,0$ & $80,6 \pm 1,0$ & $75,2 \pm 1,0$ \\
\hline Nitrato $\left(\mathrm{mg} \mathrm{L}^{-1}\right)$ & $14,0 \pm 3,4$ & $16,0 \pm 2,1$ & $19,0 \pm 3,9$ & $17,0 \pm 2,7$ \\
\hline Fósforo Total (mg. $\left.\mathrm{L}^{-1}\right)$ & $0,9 \pm 0,1$ & $0,7 \pm 0,1$ & $1,2 \pm 0,1$ & $1,0 \pm 0,1$ \\
\hline Potássio (mg. $\left.\mathrm{L}^{-1}\right)$ & $35,0 \pm 3,8$ & $33,0 \pm 4,3$ & $32,0 \pm 3,9$ & $30,0 \pm 3,6$ \\
\hline Cloreto (mg. $\left.\mathrm{L}^{-1}\right)$ & $<L Q^{*}$ & $<L Q$ & $<\mathrm{LQ}$ & $<L Q$ \\
\hline Acidez $\left(\mathrm{mg} \cdot \mathrm{L}^{-1}\right)$ & $20,0 \pm 0,1$ & $20,0 \pm 0,1$ & $20,0 \pm 0,1$ & $20,0 \pm 0,1$ \\
\hline Alcalinidade $\left(\mathrm{mg} \cdot \mathrm{L}^{-1}\right)$ & $110,0 \pm 0,1$ & $70,0 \pm 0,1$ & $70,0 \pm 0,1$ & $60,0 \pm 0,2$ \\
\hline Dureza $\left(\mathrm{mg} \cdot \mathrm{L}^{-1}\right)$ & $107,0 \pm 0,1$ & $73,0 \pm 0,2$ & $65,0 \pm 0,2$ & $49,0 \pm 0,1$ \\
\hline Vazão (L.s $\left.{ }^{-1}\right)$ & 0,01 & - & 240 & - \\
\hline
\end{tabular}

* $\mathrm{LQ}=$ limite de quantificação.

Conforme observado na Tabela 1 os valores de potencial hidrogeniônico $(\mathrm{pH})$ encontrados nos pontos de amostragem estão dentro da faixa permitida na Resolução CONAMA n. 357/05 para águas doces de Classe 2, como as do Córrego Lanoso, valores de $\mathrm{pH}$ próximos a neutralidade. 
Segundo Heller e Pádua (2010) o pH da água mede a atividade dos íons hidrogênio. De acordo com Heller e Pádua (2010), por conta da capacidade de tamponamento, as águas naturais, geralmente, possuem $\mathrm{pH}$ perto da neutralidade, mas há a possibilidade da ocorrência de alteração natural do pH por conta das características do solo, da presença dos ácidos húmicos e fúlvicos dissolvidos ou de grandes atividades fotossintéticas (redução do $\mathrm{CO}_{2}$ ).

A turbidez é a interferência da concentração das partículas suspensas (areia, argila, matéria orgânica, silte, colóides, plâncton, dentre outros) na água, obtida através do efeito da dispersão da luz que essas partículas provocam. As águas superficiais possuem valores de turbidez entre 1 e 1000 UNT, sendo que a turbidez está inteiramente relacionada com as características da bacia hidrográfica (DI BERNARDO; PAZ, 2008).

Observou-se que o valor máximo de turbidez foi de 7,2 UNT no P4 e o mínimo de 1,93 UNT no P1. Assim, apresentam-se dentro do especificado na Resolução CONAMA n. 357/05 para águas doces de Classe 2 (até 100 UNT) e estão entre o esperado para águas superficiais. Já sua variação pode estar relacionada com os materiais lixiviados para o leito do Córrego Lanoso em virtude da intensidade das atividades de pastagem e agricultura exercidas no local, associado ainda às baixas declividades do curso de água principal e da bacia (TORRES, 2008).

A condutividade elétrica mede a capacidade que a água tem para conduzir corrente elétrica por conta dos minerais presentes nela, sendo que nas águas naturais (classe 2) os valores variam entre $50 \mu \mathrm{S} . \mathrm{cm}^{-1}$ e $500 \mu \mathrm{S} . \mathrm{cm}^{-1}$ (DI BERNARDO; PAZ, 2008). No presente estudo, a condutividade foi decrescente entre os pontos analisados, cujo valor máximo foi no P1 de $196,3 \mu \mathrm{S} . \mathrm{cm}^{-1}$ e o mínimo no P4 de $72,9 \mu \mathrm{S} . \mathrm{cm}^{-1}$, entretanto, estão dentro do intervalo mencionado. Esse decréscimo na condutividade está relacionado com o efeito da diluição na concentração das espécies minerais (íons livres) ocasionado pelo aumento da vazão ao longo do curso do Córrego Lanoso.

Os sólidos totais também se encontraram dentro da faixa aceita pela Resolução CONAMA n. 357/05 em todos os pontos, sendo que os valores encontrados de 170 mg. $\mathrm{L}^{-1}$ e $60 \mathrm{mg}^{-1} \mathrm{~L}^{-1}$ foram o maior (P2) e o menor (P4), respectivamente. Os sólidos totais são constituídos pelos sólidos dissolvidos e pelos sólidos em suspensão presentes no meio, podendo então apresentar, em função dos pontos de amostragem, um maior número em suspensão, também confirmado pelo aumento da turbidez (RAMOS et al., 2010).

Sabe-se que a presença de oxigênio dissolvido é fundamental para a vida aquática, bem como para os elementos que efetuam a depuração em águas naturais. A quantidade de oxigênio das águas naturais pode oscilar com a temperatura, a salinidade, a turbulência, a atividade fotossintética das algas e plantas e com a pressão atmosférica. Além disso, a solubilidade do oxigênio dissolvido diminui à medida que a temperatura e a salinidade aumentam. É de conhecimento que níveis menores que $5 \mathrm{mg} \cdot \mathrm{L}^{-1}$ podem prejudicar o funcionamento e a sobrevivência de comunidades biológicas, e valores inferiores que $2 \mathrm{mg} \cdot \mathrm{L}^{-1}$ podem causar uma mortalidade excessiva de peixes (HELLER; PÁDUA, 2010).

Em relação ao parâmetro Oxigênio Dissolvido (OD) e percentual de Saturação de Oxigênio Dissolvido, nota-se que ambos foram crescentes entre os pontos e todos os valores de OD foram maiores que $5 \mathrm{mg} \cdot \mathrm{L}^{-1}$, o que significa que este parâmetro está em consonância com a Resolução CONAMA n. 357/05 para águas doces de Classe 2. As pequenas variações ao longo do Lanoso podem ser explicadas pelo aumento da turbulência e com a entrada dos afluentes. 
De acordo com Brito (2008), em águas naturais, o parâmetro cor está associado às substâncias dissolvidas que se encontram neste meio. Estas substâncias podem ser de origem natural, como a decomposição da matéria orgânica (ácidos húmicos e fúlvicos) e inorgânica, compostos inorgânicos como ferro e manganês presentes na composição do solo, bem como de origem antropogênica (esgotos domésticos e efluentes oriundos de processos industriais).

A Resolução CONAMA n. 357/05 estabelece como padrão limite para cor em rios de classe 2, o valor de $75 \mathrm{mgPt} . \mathrm{L}^{-1}$. O ponto P4 apresentou valor superior ao limite estabelecido, isso pode estar relacionado às atividades agropecuárias existentes nas proximidades da área. Segundo Von Sperling (2007) além das atividades antrópicas que influenciam diretamente na alteração da cor das águas naturais, há também alguns minerais dissolvidos no corpo hídrico que podem causar coloração, como por exemplo, o ferro e manganês, os quais estão relacionados com a geologia dos solos da região.

$\mathrm{A} \mathrm{DBO}_{5}$ mede a quantidade de oxigênio necessária pelos microrganismos na degradação da matéria orgânica biodegradável, sob condições aeróbicas, em 5 dias, a $20^{\circ} \mathrm{C}$ (DI BERNARDO; PAZ, 2008). Águas que não se encontram poluídas possuem valores menores que $5 \mathrm{mg} \cdot \mathrm{L}^{-1}$ de $\mathrm{DBO}$. Assim, para valores mais elevados são necessário que seja analisado as possíveis causas (HELLER; PÁDUA, 2010).

Segundo Babbitt et al. (1962) apud Heller e Pádua (2010), altos valores de DBO indica poluição orgânica. Em todos os pontos de coleta os valores de $\mathrm{DBO}_{5}$ foram superiores a $70 \mathrm{mg} \cdot \mathrm{L}^{-1}$, portanto, acima do permitido na Resolução CONAMA n. 357/05 para águas doces de Classe $2\left(\mathrm{DBO}_{5}\right.$ dias a $20^{\circ} \mathrm{C}$ até $\left.5 \mathrm{mg} / \mathrm{L} \mathrm{O}_{2}\right)$.

O parâmetro $\mathrm{DBO}$ é um dos principais indicadores de poluição nas águas e acredita-se que tais valores encontrados estão associados ao recebimento de carga poluidora, proveniente das atividades desenvolvidas ao longo do Córrego Lanoso e da assimilação do corpo receptor a essa carga. Embora os valores tenham sido altos, não houve decréscimo do OD nos pontos amostrados, e tal fato pode indicar duas situações: a primeira é que esta carga poluidora pode ter sido recentemente lançada no córrego, em relação ao dia da amostragem, e com isso ainda não tinha sido assimilada pelo mesmo; a segunda é que a vazão e a autodepuração do Córrego Lanoso foram eficientes para tal demanda, de forma que a demanda potencial de oxigênio no meio e a reaeração natural fosse satisfatória para que ocorresse a estabilização desses compostos orgânicos biodegradáveis, perante a baixa sinuosidade baixa do canal que favorece a maior velocidade na dispersão de poluentes além da reduzida declividade do leito do Córrego Lanoso.

Vale ressaltar que a Demanda Química de Oxigênio (DQO) resulta das partes que são estabilizadas quimicamente, ou seja, biodegradável (ação bacteriana), mas também não biodegradável (LIBÂNIO, 2010). A DQO deve ser observada em consonância a DBO. Segundo Von Sperling (1995), a relação $\mathrm{DQO} \mathrm{DBO}_{5}$, fornece indicações sobre a biodegradabilidade do efluente e do método de tratamento a ser utilizado.

A relação $\mathrm{DQO} \mathrm{DBO}_{5}$ nos pontos de coleta foi 1,74 (P1), 1,76 (P2), 1,73 (P3) e 1,50 (P4). Sendo assim, os pontos P2 e P4 apresentaram a menor e a maior biodegradabilidade, respectivamente. Como em todos os pontos a relação foi inferior a 2,5, infere-se que, se necessário, há possibilidade de um tratamento biológico para o Córrego Lanoso. A resolução CONAMA n. 357/05 não estabelece limites para o parâmetro em questão.

O íon nitrato, geralmente, se encontra nas águas naturais oriundo de rochas ígneas, de áreas de drenagem e da decomposição de matéria orgânica. Mas a utilização 
de fertilizantes a partir de nitrato inorgânico, lançamento de despejos domésticos ou industriais, podem elevar suas concentrações nas águas superficiais. Elevadas concentrações de nitrato, em águas superficiais, podem instigar o crescimento de plantas aquáticas e do fitoplâncton (HELLER; PÁDUA, 2010). Em todos os pontos amostrados no presente estudo o teor de nitrato ficou acima do limite estabelecido pela resolução CONAMA n. 357/05 para águas doces de classe 2, o qual corresponde a 10,0 mg. $\mathrm{L}^{-1}$. Esse aumento de nitrato está relacionado com as atividades agropecuárias exercidas no local, principalmente, o plantio de cana-de-açúcar.

Em todos os quatro pontos de amostragem no Córrego Lanoso, o teor de fósforo total foi superior ao limite máximo estabelecido pela Resolução CONAMA n. 357/05 (0,02 $\mathrm{mg} \cdot \mathrm{L}^{-1} \mathrm{P}$ ) para águas doces de classe 2. Sabe-se que o fósforo é o principal limitante ao desenvolvimento de algas e plantas aquáticas, uma vez que se apresenta em menor quantidade que o nitrogênio e geralmente na forma de fosfato derivado do ácido fosfórico. O fosfato expressa-se nos corpos d'água na forma orgânica ou inorgânica, particulada ou dissolvida, sendo que a soma dessas quatro frações constitui-se o fosfato total. As formas mais comuns nos corpos d'água (ortofosfatos e polifosfatos) podem ser provenientes do lançamento de esgotos domésticos e industriais, fertilizantes e lixiviação de criatórios de animais (LIBÂNIO, 2010).

Assim como o nitrato, o fósforo total também apresentou altos valores nos pontos amostrados, sendo ambos, os principais macros elementos utilizados na composição dos fertilizantes. O que justifica ainda mais que tais parâmetros e seus altos valores estão relacionados às atividades agropecuárias que são desenvolvidas ao longo da área do Córrego Lanoso. O uso excessivo de fertilizantes (NPK) e os excrementos animais são considerados as principais fontes difusas de contaminação dos corpos hídricos em áreas agrícolas. É conhecido que o aumento nos teores de fósforo e nitrato pode favorecer a proliferação de algas no canal do Lanoso (FUCHS, 2012).

O potássio é um macronutriente que pode ser encontrado nas águas naturais em baixas concentrações, sendo sua origem natural relacionada à lixiviação das rochas. As principais fontes de potássio são às atividades antrópicas, como agricultura e processos industriais, onde esse elemento é empregado (PIRATOBA, 2017; ZUIN et al., 2009). Observou-se que a concentração de potássio foi diminuindo ao longo dos pontos de amostragem em consequência do aumento do fator de diluição provocado pelo incremento da vazão do Lanoso. Assim, a máxima concentração foi encontrada no P1(35 mg. $\left.\mathrm{L}^{-1}\right)$ e a mínima no P4 (30 mg. $\left.\mathrm{L}^{-1}\right)$. A resolução CONAMA 357/05 não estabelece limites para tal parâmetro.

Não foi encontrado cloreto em nenhuma amostra. O íon cloreto não colabora de forma significante nos processos geoquímicos e biológicos que ocorrem nos meios naturais. A presença de cloreto em águas naturais de uma região indica poluição, devido ao fato do cloreto ser conservativo e os esgotos domésticos conter elevadas concentrações deste íon (HELLER; PÁDUA, 2010). Além disso, o cloreto aumenta a condutividade elétrica da água e o poder corrosivo nas ligas metálicas constituintes das tubulações do sistema de distribuição de água e esgotos (DI BERNARDO; PAZ, 2008).

Sendo assim, a ausência de cloreto demonstra que nos pontos avaliados não foi observada a dissolução de minerais ou intrusão de águas salinas no que se refere as possíveis origens naturais deste íon. Quanto à origem antropogênica, pode-se inferir que não há fontes significativas de despejos domésticos, industriais ou águas utilizadas em irrigação. 
Observou-se que a acidez foi constante em todos os pontos (20 mg. $\left.\mathrm{L}^{-1}\right)$, mas a alcalinidade apresentou variações, com a maior medida em P1 (110 mg. $\left.\mathrm{L}^{-1}\right)$ e a menor em P4(60 mg. $\left.\mathrm{L}^{-1}\right)$. A acidez é a capacidade da água em neutralizar bases devido à presença de ácidos minerais fortes, ácidos fracos (como o ácido carbônico, ácidos fúlvicos e húmicos) e sais de metais hidrolisados como o sulfato de alumínio e o cloreto férrico (DI BERNARDO; PAZ, 2008).

Já a alcalinidade é a capacidade da água em neutralizar ácidos, por conta, principalmente, da concentração de carbonatos, bicarbonatos e hidróxidos, mas pode ter contribuições de boratos, fosfatos, silicatos e outros componentes básicos. Além de atuar como um sistema tampão (capacidade de atenuar as variações de $\mathrm{pH}$ ), a alcalinidade também é um reservatório de carbono inorgânico que é essencial no processo de fotossíntese, determinando a habilidade da água sustentar 0 crescimento dos fitoplânctons e de macrófitas submersas (HELLER; PÁDUA, 2010).

Os valores de dureza da água foram decrescentes em função dos pontos amostrados. Com isso, o maior valor foi no $\mathrm{P} 1$ (107 $\mathrm{mg} \cdot \mathrm{L}^{-1}$ de $\left.\mathrm{CaCO}_{3}\right)$ e o menor no P4 (49 mg. $\mathrm{L}^{-1}$ de $\mathrm{CaCO}_{3}$ ). Habitualmente, a dureza acontece devido a associação do cálcio ao bicarbonato transformando-se em carbonato de cálcio, por aquecimento ou elevação do $\mathrm{pH}$ (dureza temporária), mas também ocorre a dureza proveniente dos cátions associados a outros ânions, dureza permanente (HELLER; PÁDUA, 2010). A dureza revela a natureza geológica da bacia hidrográfica, cuja característica é mais expressa em regiões calcárias e de menor grau em regiões de terrenos arenosos ou argilosos. Ademais, podese classificar como água mole ou branda valores inferiores a $50 \mathrm{mg} \cdot \mathrm{L}^{-1}$ de $\mathrm{CaCO}_{3}$ e de dureza moderada entre 50 e 150 mg. $\mathrm{L}^{-1}$ de $\mathrm{CaCO}_{3}$ (LIBÂNIO, 2010), sendo que tais faixas englobam os valores obtidos no estudo.

Desse modo, a dureza correspondente à alcalinidade é a dureza de carbonato, responsável pela precipitação em elevadas temperaturas. Os resultados (Tabela 1) mostram a relação entre dureza e alcalinidade, onde as duas decaem proporcionalmente ao longo dos pontos. Como os maiores valores de dureza foram identificados no ponto de menor vazão (P1) e a fonte mais provável é a dissolução de rochas calcárias, pode-se inferir que este curso d'água ainda não recebe contribuições de despejos industriais.

Após análise conjunta dos resultados dos parâmetros de qualidade da água, verifica-se que não houve um padrão uniforme no comportamento físico-químico de qualidade da água ao longo do Córrego Lanoso. Como não foram identificadas fontes pontuais de poluição, o uso do solo da bacia (predominantemente agropecuário) atua como uma fonte difusa de poluição dessa bacia, o que justifica as variações dos resultados supracitados de forma não uniforme. 


\section{Potencial de autodepuração do Córrego Lanoso}

A água é um recurso natural intensamente utilizado, sendo fundamental para a vida, bem como para as atividades econômicas. Em alguns casos, a demanda de água pode superar a oferta em termos quantitativos bem como qualitativos, cuja disponibilidade pode ser prejudicada pela poluição recebida. Assim, os recursos hídricos podem ser utilizados por atender diferentes necessidades, porém a crescente escassez desse recurso e o aumento da demanda podem ocasionar conflitos quanto ao uso da água (FREITAS et al., 2011).

Para evitar tais conflitos, no curso d'água estudado foi avaliado diferentes cenários considerando a carga máxima assimilada para cada trecho do Córrego Lanoso, como mostrado na Figura 2.

A modelagem para avaliação da carga máxima assimilada é uma importante ferramenta para gestão dos recursos hídricos, podendo direcionar o desenvolvimento econômico na bacia hidrográfica, pois através dela avaliamos a capacidade de suporte ou de autodepuração do curso d'água (processo natural de recuperação realizado por meio de processos físicos, químicos e biológicos).

A importância da compreensão da capacidade de autodepuração está relacionada a carga de efluente que poderá ser recebida em cada trecho estudado. A introdução de matéria orgânica resulta indiretamente no consumo de oxigênio dissolvido, pois há o consumo de OD nos processos de decomposição, e isso tem diversas implicações do ponto de vista ambiental. Assim, a autodepuração está relacionada ao restabelecimento do equilíbrio no meio aquático, após alterações induzidas pelos despejos afluentes (VON SPERLING, 2005).

Para estimativa da carga máxima assimilada em cada trecho, os valores de entrada de vazão e concentração de um efluente hipotético foram testados (simulando um lançamento pontual de carga) visando a redução do OD até $5 \mathrm{mg} . \mathrm{L}^{-1}$. As vazões dos pontos 2 e 4 foram consideradas iguais a 0,01 L.s $^{-1}$ e 240 L.s ${ }^{-1}$ respectivamente. Na simulação considerou-se que o trecho entre os pontos 1 e 2 é uniforme. A mesma consideração foi feita para o trecho entre os pontos 3 e 4 (Figura 1).Os resultados encontrados para os cenários de 1 a 4 estão apresentados na Tabela 2. 
Figura 2. Cenários avaliados considerando a carga máxima assimilada por cada ponto amostrado, sendo: a) Calibração do OD; b) Cenário criado para o ponto 1 ; c) Cenário criado para ponto 2; d) Cenário criado para ponto 3; e) Cenário criado para o ponto 4; f) Cargas máximas assimiladas para os quatro ponto sem estudo do Córrego Lanoso.
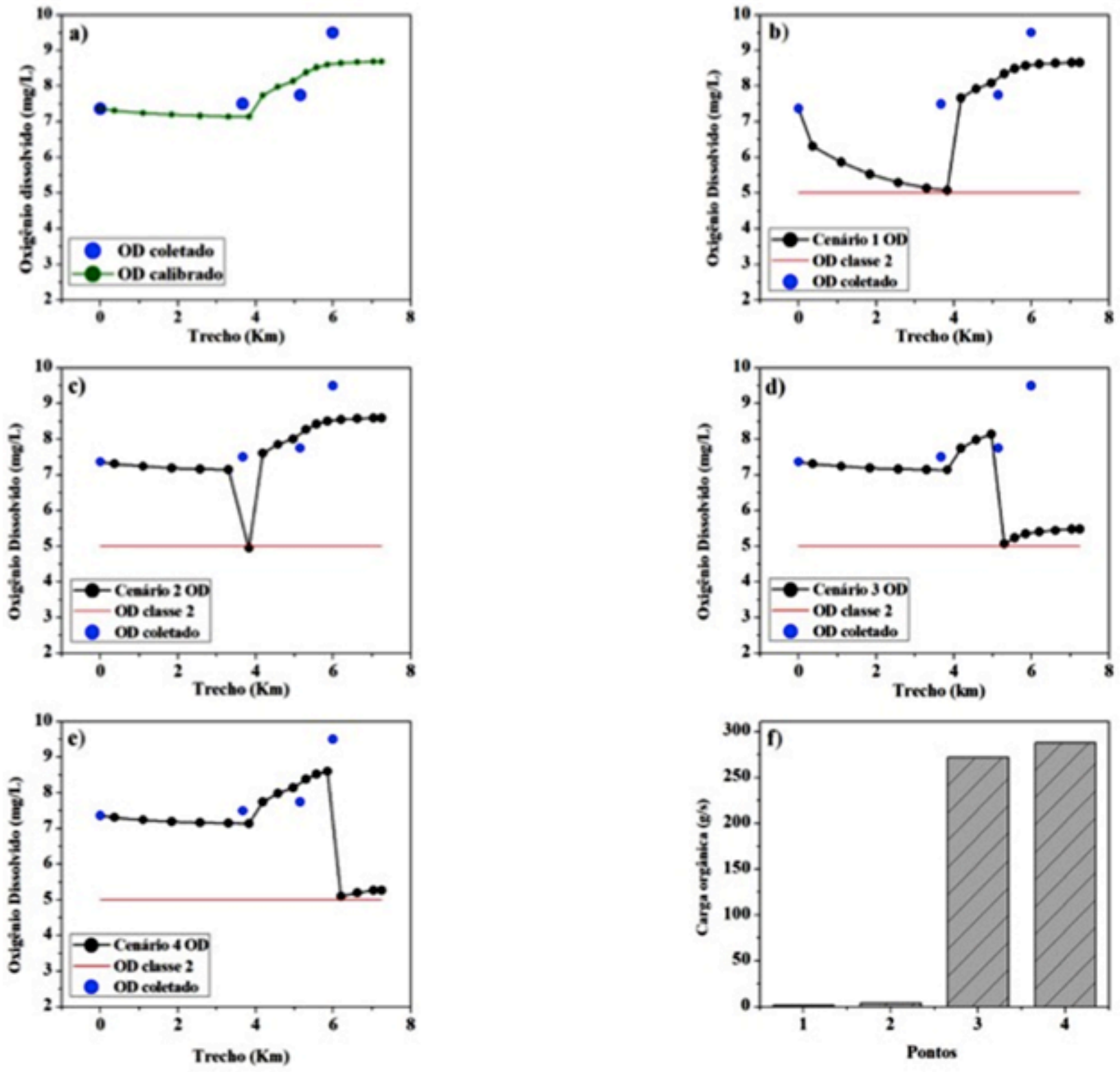

Tabela 2. Carga máxima assimilada por cada trecho do Córrego Lanoso

\begin{tabular}{|c|c|c|c|c|}
\hline $\begin{array}{c}\text { Unidade De } \\
\text { Carga }\end{array}$ & Ponto 1 & Ponto 2 & Ponto 3 & Ponto 4 \\
\hline g.s. ${ }^{-1}$ & 1,20 & 4,16 & 272,00 & 288,00 \\
\hline g.dia ${ }^{-1}$ & 103.680 & 359.424 & 23.500 .800 & 24.883 .200 \\
\hline $\mathrm{mg}^{\mathrm{dia}}{ }^{-1}$ & 103.680 .000 & 359.424 .000 & 23.500 .800 .000 & 24.883 .200 .000 \\
\hline $\mathrm{kg} \cdot \mathrm{dia}^{-1}$ & 103,68 & 359,42 & $23.500,80$ & $24.883,20$ \\
\hline
\end{tabular}


Considerando a tendência agropecuária da bacia do Córrego Lanoso foram comparados os resultados dos cenários avaliados com as características das águas residuárias, de acordo com Von Sperling (2005), dos gêneros alimentícios, criador de animais confinados, sucroalcooleira e couro de curtume (Quadro 1).

Quadro 1. Valores de referência para lançamentos de carga orgânica

\begin{tabular}{|c|c|c|c|c|c|}
\hline Gênero & Tipo & $\begin{array}{l}\text { Unidade de } \\
\text { Produção }\end{array}$ & $\begin{array}{c}\text { Carga } \\
\text { Específica } \\
\left(\text { kg.unid }^{-1}\right)\end{array}$ & $\begin{array}{c}\text { Equivalente } \\
\text { Populacional } \\
\left(\mathrm{hab}^{-1} \cdot \text { unid }^{-1} \cdot \mathrm{d}^{-1}\right)\end{array}$ & $\mathrm{DBO}_{5}\left(\mathrm{mg} \cdot \mathrm{L}^{-1}\right)$ \\
\hline \multirow{4}{*}{ Alimentício } & $\begin{array}{l}\text { Laticínio sem } \\
\text { Queijaria }\end{array}$ & $1000 \mathrm{~L}$ leite & $1-5$ & $20-100$ & $300-5000$ \\
\hline & Laticínio com & $1000 \mathrm{~L}$ leite & & & \\
\hline & Queijaria & & $5-40$ & $100-800$ & $500-8000$ \\
\hline & Matadouros & $\begin{array}{c}1 \text { boi } \\
2,5 \text { porcos }\end{array}$ & $0,3-5$ & $10-100$ & $1000-5000$ \\
\hline \multirow{3}{*}{$\begin{array}{l}\text { Criatórios de } \\
\text { animais } \\
\text { confinados }\end{array}$} & Suíno & & 2 & $35-100$ & $10.000-50.000$ \\
\hline & Bovino & $\mathrm{t}$ viva dia & 1,8 & $65-150$ & $10.000-50.000$ \\
\hline & Ovinos & & 0,9 & $15-20$ & $2.000-3.000$ \\
\hline $\begin{array}{c}\text { Sucro } \\
\text { alcooleira }\end{array}$ & Destilação de álcool & $\begin{array}{c}1 \mathrm{t} \text { cana } \\
\text { processada }\end{array}$ & 220 & 4.000 & 3.500 \\
\hline $\begin{array}{l}\text { Couro e } \\
\text { curtume }\end{array}$ & Curtume & $\begin{array}{l}1 \mathrm{t} \text { de pele } \\
\text { processada }\end{array}$ & $20-150$ & $1.000-3.500$ & $1.000-4.000$ \\
\hline
\end{tabular}

Fonte: Von Sperling, 2005.

Correlacionando as cargas encontradas nos 4 cenários com as cargas específicas de referência citadas por Von Sperling (2005), a bacia do Córrego Lanoso está apta a receber as atividades apresentadas na (Tabela 3 ).

Tabela 3. Produção suportada em cada um dos pontos (em números de unidade de produção)

\begin{tabular}{|c|c|c|c|c|c|c|c|}
\hline \multirow[t]{2}{*}{ Gênero } & \multirow[t]{2}{*}{ Tipo } & \multirow[t]{2}{*}{$\begin{array}{l}\text { Unidade de } \\
\text { Produção }\end{array}$} & $\begin{array}{c}\text { Carga } \\
\text { específica }\end{array}$ & $\begin{array}{c}\text { Carga } \\
\text { Máxima } \\
\text { Ponto } 1 \\
103,68 \\
\text { kg.dia- }\end{array}$ & $\begin{array}{c}\text { Carga } \\
\text { Máxima } \\
\text { Ponto } 2 \\
359,42 \text { kg.dia }\end{array}$ & $\begin{array}{c}\text { Carga } \\
\text { Máxima } \\
\text { Ponto } 3 \\
23.500,80 \\
\text { kg.dia }^{-1}\end{array}$ & $\begin{array}{c}\text { Carga } \\
\text { Máxima } \\
\text { Ponto } 4 \\
24.883,20 \\
\text { kg.dia }^{-1}\end{array}$ \\
\hline & & & $\left(\right.$ kg.unid $\left.^{-1}\right)$ & \multicolumn{4}{|c|}{$\begin{array}{l}\text { Produção Suportada números de unidades de } \\
\text { produção }\end{array}$} \\
\hline \multirow{4}{*}{ Alimentício } & $\begin{array}{l}\text { Laticínio } \\
\text { sem } \\
\text { Queijaria }\end{array}$ & $\begin{array}{l}1000 \mathrm{~L} \\
\text { leite }\end{array}$ & 5,00 & 21 & 72 & 4.700 & 4.977 \\
\hline & $\begin{array}{l}\text { Laticínio } \\
\text { com } \\
\text { Queijaria }\end{array}$ & $\begin{array}{c}1000 \mathrm{~L} \\
\text { leite }\end{array}$ & 40,00 & 3 & 9 & 588 & 622 \\
\hline & \multirow{2}{*}{ Matadouros } & 1 boi & \multirow{2}{*}{5,00} & 21 & 72 & 4.700 & 4.977 \\
\hline & & 2,5 porcos & & 21 & 72 & 4.700 & 4.977 \\
\hline \multirow{3}{*}{$\begin{array}{l}\text { Criatórios de } \\
\text { animais } \\
\text { confinados }\end{array}$} & Suíno & \multirow{3}{*}{ t viva dia } & 2 & 52 & 180 & 11.750 & 12.442 \\
\hline & Bovino & & 1,80 & 58 & 200 & 13.056 & 13.824 \\
\hline & Ovinos & & 0,90 & 115 & 399 & 26.112 & 27.648 \\
\hline $\begin{array}{l}\text { Sucro } \\
\text { alcooleira }\end{array}$ & $\begin{array}{l}\text { Destilação } \\
\text { de álcool }\end{array}$ & $\begin{array}{l}1 \mathrm{t} \text { cana } \\
\text { processada }\end{array}$ & 220 & 0 & 2 & 107 & 113 \\
\hline $\begin{array}{l}\text { Couro e } \\
\text { curtume }\end{array}$ & Curtume & $\begin{array}{l}1 \mathrm{t} \text { de pele } \\
\text { processada }\end{array}$ & 150 & 1 & 2 & 157 & 166 \\
\hline
\end{tabular}


Analisando a carga máxima que pode ser assimilada em cada um dos pontos, verifica-se que as produções que podem ser recebidas nos Pontos 1 e 2 são de menor escala, visto que a capacidade de suporte destes pontos é menor, portanto mais atrativa para atividades com produções menores, geralmente associadas a agricultura familiar. Já os Pontos 3 e 4 estão aptos a receber efluentes de produções maiores em escala industrial, considerando os limites de unidades produtivas apresentados na Tabela 3.

\title{
CONCLUSÕES
}

Em relação aos parâmetros de qualidade da água avaliados somente a cor, $\mathrm{DBO}_{5}$, nitrato e fósforo não atenderam aos limites máximos estabelecidos pela legislação vigente para Classe 2. Essas alterações estão relacionadas coma as atividades agropecuárias desenvolvidas nas proximidades da bacia do Córrego Lanoso. Não há um padrão uniforme no comportamento dos parâmetros ao longo do córrego, concluindo-se que as fontes atuais de poluição devem ocorrer de forma difusa.

O modelo QUAL2K permitiu estimar o potencial de autodepuração dos trechos do Córrego Lanoso.

A carga máxima admissível pelo Córrego Lanoso foi de $288 \mathrm{~g} . \mathrm{s}^{-1}$, cujos pontos que estão aptos a receberem maior carga poluidora estão localizados a jusante da bacia (pontos 3 e 4), onde é possível ampliar a produtividade em maior escala nos gêneros alimentícios, agropecuária e sucroalcooleiro, de acordo com a ocupação atual da bacia.

Nos pontos a montante (1 e 2), a carga máxima admissível suportada através da autodepuração é mais baixa, assim recomenda-se que nestas áreas sejam mantidos os usos recorrentes, com acréscimo restrito à agricultura familiar de subsistência.

\section{REFERÊNCIAS}

\author{
ABDALA, V. L. Zoneamento Ambiental da bacia do alto curso do Rio Uberaba-MG \\ como subsídio para gestão do recurso hídrico superficial. Dissertação (Pós- \\ Graduação em Geografia), Universidade Federal de Uberlândia, 2005.
}

APHA (2008). Standart Methods for the Examination of Water and Weste water. American Public Health Association, American Water Works Association, Water Environmental Federation, $20^{\text {th }}$ ed. Washington.

BOTTINO, F. Estudo experimental e matemático de qualidade da água com base na ecohidrologia fluvial de pequenas bacias: estudo de caso do rio Canha, baixo Ribeira de Iguape, SP. 188p.Dissertação (Mestrado em Hidráulica e Saneamento) - Universidade de São Paulo, 2008.

BRASIL. Resolução CONAMA n³57, de 17 de março de 2005. Dispõe sobre a classificação dos corpos de água e diretrizes ambientais para o seu enquadramento, bem como estabelece as condições e padrões de lançamento de efluentes, e dá outras providências. Diário Oficial da União, n. 053, p. 58-63, 18 mar. 2005.

BRITO, D. C. Aplicação do Sistema de Modelagem da Qualidade da Água QUAL2KW em Grandes Rios: O Caso do Alto e Médio Rio Araguari - AP. 144p. Dissertação (Mestrado em Biodiversidade Tropical): Universidade Federal do Amapá, 2008. 
CARVALHO, T. M. Técnicas de medição de vazão por meios convencionais e não convencionais. Revista Brasileira de Geografia Física, v. 01, n.01, p. 73-85, 2008. CHAPRA, S. C. Numerical methods for engineers. 5th ed. Boston: McGraw-Hill, 926 p., 2006.

DI BERNARDO, L; PAZ, L.P.S. Seleção de Tecnologias de Tratamento de Água. São Carlos: LDIBE LTDA, 2008.

FLECK, L; TAVARES, M. H. F; EYNG, E. Especificidades e importância de modelos matemáticos de qualidade da água. Revista Eixo, v.2, n.1, 2013.

FRAGA, K. P. et al. Modelo matemático Two-echelon Capacitated Vehicle Routing Problem para a logística de distribuição de encomendas. Transportes, v.24, n.3, p. 81-89, 2016.

FREITAS, M. B.; BRILHANTE, O. M.; ALMEIDA, L. M. Importância da análise de água para a saúde pública em duas regiões do Estado do Rio de Janeiro: enfoque para coliformes termotolerantes, nitrato e alumínio. Cad. Saúde Pública, v. 17, n. 3, p. 651660, 2011.

FUCHS, C. R. Classificação da qualidade da água do Córrego Lanoso, Uberaba MG. 67 p. Dissertação (Doutorado em Agronomia): Universidade Estadual Paulista, 2012.

HELLER, L; PÁDUA, V. L. Abastecimento de água para consumo humano. 2. ed. Belo Horizonte: UFMG, 2010.

LIBÂNIO, M. Fundamentos de qualidade e tratamento de água. 3. ed. Campinas: Átomo, 2010.

PINA et al. Análise temporal do uso da terra em bacias hidrográficas utilizando sistema de informação geográfica. XIII Congresso Nacional de Meio Ambiente de Poços De Caldas. 2016.

PIRATOBA, A. R. A. et al. Caracterização de parâmetros de qualidade da água na área portuária de Barcarena, PA, Brasil. Revista Ambiente \& Água, v. 12 n. 3, 2017.

QUEIROZ et al. Influência do uso do solo na qualidade da água de uma microbacia hidrográfica rural. Revista Verde de Agroecologia e Desenvolvimento Sustentável, v.5, n.4, p.200-2010, 2010.

SALLA, M. R. et al. Viabilidade técnica de implantação de sistema de aproveitamento de água pluvial para fins não potáveis em universidade. Amb. Construído, v.2, n.1, p.167181, 2013.

SILVA, P. E. A influência da mata ciliar na qualidade da água em dois rios na área rural de Foz do Iguaçu - PR Foz do Iguaçu. Faculdade Dinâmica de Cataratas, União Dinâmica de Faculdade Cataratas, 2009. 
RAMOS et al. Avaliação da qualidade da água dos mananciais superficiais do projeto Pólo de fruticultura irrigada São João - Portal Nacional - TO. Projeto (Graduação em Tecnologia em Gestão Ambiental), Faculdade Católica de Tocantins, p. 79, 2010.

SEMAM - SECRETARIA MUNICIPAL DO MEIO AMBIENTE. Plano de Manejo APA Rio Uberaba.Uberaba, Brasil, 90p.,2007.

TORRES, J.L.R. et al. Diagnóstico ambiental e análise morfométrica da microbacia do Córrego Lanoso em Uberaba-MG. Caminhos de Geografia, v.9, n.25, p1-11, 2008.

VON SPERLING, M. Estudos de modelagem da qualidade da água de rios. Belo Horizonte: UFMG,. v.7. 452 p.,2007.

VON SPERLING M. Princípios do tratamento biológico de águas residuárias: Introdução à qualidade das águas e ao tratamento de esgotos. Departamento de Eng. San. e Ambiental -UFMG. Belo Horizonte, v.1, 240 p., 1995.

VON SPERLING, M. Introdução à qualidade das águas e ao tratamento de esgotos. 3. ed. Belo Horizonte: Departamento de Engenharia Sanitária e Ambiental, 2005.

ZUIN, V. G.; IORIATTI, M. C. S.; MATHEUS C. E. O emprego de parâmetros físicos e químicos para a avaliação da qualidade de águas naturais: uma proposta para a educação química e ambiental na perspectiva CTSA. Química Nova na Escola, v. 31. 2009.

Recebido em: 17/11/2018

Aprovado em: 01/03/2019 